\title{
The Home in the Information Society
}

\author{
Andy SLOANE \\ CONTACT Research Group, School of Computing and IT, \\ University of Wolverhampton, WOLVERHAMPTON, U.K. \\ A.Sloane@wlv.ac.uk
}

\begin{abstract}
This chapter looks at the position occupied by the home as the central focus of the information society. A working definition of the home is used and various interactions and activities that take place in the home are discussed with relation to the home, and its changing place in the move to an information society. The chapter also discusses various information activities that impinge upon the function of everyday life in the home including the use of information and information systems. Finally some of the consequences of the move to an information-based model of the home are outlined.
\end{abstract}

Key words Home, cyberspace, inter-personal communication, interaction, design, information system.

\section{BACKGROUND}

This chapter is a review of research carried out by members of IFIP working group 9.3 (Home-Oriented Informatics and Telematics, HOIT) and others. It is not a comprehensive statement of the state of global research in HOIT but a snapshot of various areas of work and does not attempt to cover this wideranging and disparate field of work. It concentrates on areas that are, or should be, of current concern to designers and users of home systems. The conference proceedings of the working group have formed the basis of the sources used for the chapter and these are supplemented by significant sources from outside the working group. 


\section{INTRODUCTION}

There are many functions which can be said to epitomise the "Information Society". What is common in many cases is the focus of these functions being the home environment and the interactions that take place within the home and between home dwellers, others in society and the systems and facilities of everyday life.

Much of current industrial society is based around the concept of work and in particular the "workplace". This model of the industrial society grew up around the separation of the home and the workplace. The movement towards an information-based society has far-reaching consequences for the home and the relative positions of home and work. A good deal of research has covered work and the home - but the focus of this chapter is the "home" function not the "work" function even though the boundary is becoming increasingly blurred. The work aspects of home life are largely omitted from this review. The chapter, therefore, attempts to outline various positions and opinions that have been expressed on the nature of home in the information society and the changes that are likely in this "home" function when movement towards a more information-based society takes place.

The chapter firstly outlines what is meant by the home, which, although a familiar concept, has many different interpretations in the world. Also, the changes that are taking place in the organisation and use of homes is covered. The next section then looks at the problems of studying the home environment and the attendant problems of obtaining data and meaningful results. The chapter then goes on to look at the way homes and society interact and the place that is occupied by the home, in its widest sense, in society. Finally the chapter concludes with a study of the effect of the information society on the home and its occupants, including the social effects of the increasing reliance on information in everyday life. One of the themes that will become clear through this chapter and others in the book is that the information society involves a blurring of boundaries. This is a central part of the argument of how the information society will affect the home and the evolution in the definition of home is a manifestation of these changes. What is also evident from work in this area is that the fabric of the home itself is not the sole area that should concern the designers but also the interactions of the people who live there with the various other objects and actors that influence their daily lives. 


\section{THE HOME}

\section{What is a home?}

The home would appear to be a simple concept. However, the usual frame of reference of the individual is too narrow to encompass a full definition of the multitude of different possible interpretations of the home concept. What one individual may consider to be a home may by others fall short of their definition by virtue of there being some serious deficiency in the make-up of either the physical structure, the occupancy, the services provided, an emotional attachment or some other area that has a bearing on their own definition.

Therefore, where one definition may seem reasonable within one cultural setting, another may be more appropriate in a different culture. A generic definition of "home" may be possible (see [1]) but it is unlikely to bear fruit in all but the simplest of scenarios. As a working definition it is possible to consider the home as being:

"the area which has the life focus for a range of individuals and their associated service needs including the structure, the occupants and activities that take place there, and their inter-relationships".

This may encompass many culturally unique definitions of the home but not all. Many researchers have used this type of definition [see, typically, 18] both implicitly and explicitly to frame their discussions. What is important to remember is that there are some shortcomings for this as an allencompassing definition but it serves well as a working definition for many different cultural environments. In the framework of Western countries it fulfils the requirements for study of the Information society and the effects that it will have upon the home in the future. However, it may be that the definition itself will need to be reviewed in the future if some of the more far-reaching consequences are realised.

There are many different definitions in the literature that may also prove useful. These include one that is based on "domestic space ... appropriated psychologically and physically" [10] and also "a collection of milieus: a territory, an expression, a collection of objects..."[19]. Whilst the former is rooted in the real-life aspects of home it incorporates some hint of the virtual in the aspects of psyche that are incorporated in it. The latter definition also uses a general approach that can include these aspects as required. Both these definitions can be used alongside the more functional one chosen here. 


\section{Organisation of the home}

The home is generally a private space which is occupied by a group of people - often a "family" with the various definitions that this involves. In some cases the home may be a set of unrelated individuals who live in the same physical space. The relationship between the individuals will have an effect on the organisation of the home and the activities that are carried out in it. For example, a family group may consist of an adult pair who work and some children who attend school giving rise to numerous activities that are likely to take place - paid and unpaid work, education, leisure and social activities among others. The occupants and their relationships to each other along with their positions in society will determine their range of activities some of which will be conducted from home.

The organisation of the home is also a factor in its place in the wider social setting of society and extended family groupings. Some homes become the focus of attention for groups while others are less likely to be used for these activities. Many factors determine the range of activities that will be conducted in the home. The move to an information-based society may change the relative weight of the factors involved or remove some of them altogether.

There are many aspects of home and the interactions that occur with them that require discussion. These include the architecture of the building, the people living in it, the technology used there, the other people involved in the lives of those that live there and wider society. These aspects of the wider definition of the home are discussed later in the chapter.

\section{The place of "home" in society}

Homes in traditional societies confer a certain "status" upon the occupiers. In some cultures this is more apparent than in others but largely true to some extent. This status is often a desirable feature of the physical structure, its location, the layout of the structure or its proximity to other homes. It is rarely a consequence of the occupants of the home but this can be a factor. The information society model will have some mitigating effect upon this status factor.

The use of communication networks and information and communication technology will remove the direct link to physical space that has traditionally been the defining statement for the home and replace this with a more information-based definition that will create a new status that will have new dependencies and new factors that will be desirable. This is not to say that all the traditional values will be replaced: mostly the new factors of the information society will add value to the existing status of 
homes but it is possible that for some users the "connections" will be more important than the structure.

\section{Changes in usage patterns}

The move to a more information-based society will also have effects on the usage patterns in the home. A typical example given is the ability to work from home more but this is only one of the many different possibilities that are available in an information society. The use of the physical space of the home is one of the factors often discussed but the ability to mould the logical, social space is found less often but is possibly as significant as the movement of work to the home.

What is evident from the study of information and communication technologies (ICT) over recent years is that people adapt technology to their interests and requirements. The growth in text messaging on mobile phones is a good case of this. The facility is fairly limited in its scope but has become very well used in certain sections of the population, particularly the young. The other technologies that are available to users have also been used and adapted to personal requirements with some being more popular than others. What seems to be evident is that users will use a technology if they see a personal benefit and not use one if there is no advantage.

The changes in use of the home will result, in part, from the take-up of different technologies by home users and the patterns of home activities will change accordingly, based on what users want to do with their environment and how they relate to the other occupants and with other homes that they are connected with. There is also the view that ICTs fundamentally affect what is meant by "home". and have "liberated our domesticity from its dependence on physical location" [5, see also 17,16$]$.

\section{STUDYING THE HOME}

The place of the definitions and the discussion around the changes to them has been necessary to help decide where the boundaries are for any study that takes place. It is clear from the previous section that the boundaries are blurring to an extent that the study of the home needs to encompass more than in the past. Many previous studies have focussed on the use of technology and have been based in the physical environment, even those that look at the virtual aspects of everyday life.

One of the areas that has seen activity in recent years has been the study of the interface between users in the home and the technology involved in the Information Society. This has been an extension to the studies that have 
been carried out over many years, which have focussed on the use of computers in the work environment. There are, however, significant differences in the approach needed and the structure of the information gathering exercise that make it difficult to obtain valid results from experiments and surveys. Much of the difficulty is caused by the nature of the home and the way in which the occupants use the home to access the services they require. There is also the problem of the presence of the observer being a factor in the behaviour of the subjects.

For example, a study of the use of television (TV) in the home has a number of choices. The experimenters can situate observers in the rooms with the subjects but this will alter their behaviour. They could use technological devices to monitor usage but will lose information as to the dynamics of choice, or they could monitor via closed-circuit television (CCTV) but still have the problem of altered behaviour. Finally the subjects could record their activity. In this case they may not be accurate in their recording! Generally researchers have used all these techniques, and sometimes a combination of them, to gather evidence. (see [9], [11])

\section{Studying home activities}

Other difficulties are caused by the difference in the type of activity that takes place in homes. A workplace study is generally directed at making the use of ICT more effective and/or efficient and achieving a designated result. The home is less goal-oriented in some respects, as the only requirement of some activities is to be "entertained", or to spend some leisure time on a pleasurable activity. It is much less easy to measure success in this type of environment than on a workplace activity. There may also be less need to finish at a certain time. For example, a person may be making an object at home to exercise a skill - the completion of the object may be a goal, but the repeated application of the skill may be just as important and the finishing time-scale may be very vague. This can apply equally well to the information society of the present day, but the activities may change. In the past the use of tools to shape objects may have been home activity and in the Information Society the use of software to develop interactive web sites may be just as common.

There are, therefore, two major problems with the study of the home. The activities that take place in the home are difficult to assess since they are not as directed as the activities that have traditionally been studied. Also, observation and recording of data is very difficult since most techniques rely on the co-operation of the subjects and tend to interfere with the very experiment that is being conducted. 


\section{HOME-BASED INTERACTIONS}

In addition to the problems that have been highlighted in the previous sections there are many different interactions that take place in the home that have an effect on the function and activities that are carried out. These range from the interaction of the home's occupants with the rest of society to the interaction with the physical environment. This section will look at five different interactional areas that are important to the study of the home in the information society.

\section{People-architecture}

The architecture of the home is often neglected. It is a factor in the move to the information society that the majority of homes have not been built with a view to being an information society home. There are many factors that could be considered in the design of structures that will be used in an information society. Amongst these are: adequate and useable space for ICT, infrastructure for ICT, the use of private domestic space for public roles in the information society and the design of the living space. Some of these issues are dealt with in the work of Junestrand and Keijer[7, 8]. The shifting boundaries between public and private spaces is also covered by Haddon and Silverstone [15].

\section{People-home}

One of the most important interactions is that between the inhabitants and the structure of the home. This has been seen in the past as the interaction between people and the building used as the home, but with the new concepts of virtual and distributed extensions to the home environment [16, 17] this interaction needs to take on an extended definition.

The concept of incorporating virtual and distributed aspects into the home is one that will be a defining characteristic of the information society. The distributed nature of home life is more a factor of modern life than of the increasing use of ICT. Family groups are more dispersed than previously, and communication technology is used to provide aspects of closeness that in the past were only possible when in proximity. It is possible to use ICT to remove the difficulties of communication caused by distribution. This will also increase as technology improves and users become more familiar with its use and possibilities. The incorporation of the virtual is a different aspect of home life. The creation of virtual existence is new, in that the participants of cyberspace do not necessarily meet in real life. These virtual aspects can become important to individuals both within 
intellectual pursuits and in the provision of affective and emotional support mechanisms. Both the distributed and the virtual tend to change the definition of home that is relevant to this discussion.

In the past, interaction between the home and its occupants was mainly in terms of shelter, security and personal space. In future, with the extension of homes into the digital arena, the interaction will include much of what is now seen as the area of human-computer interaction (HCI) in the sense that the interaction will be embedded in the structure of the home. For example, a home that is shared between different members of a family group, in two or more different physical locations, with a digital shared link between their information sources will need a sophisticated interface to make the virtual, distributed link as transparent as possible and mimic the physical proximity of the more traditional shared environment. This transparency will bring the home and the Internet more closely into the lives of the home occupants and remove the division between cyberspace and real homes.

\section{Home-society}

The interface between the home, its occupants and the rest of society has long been of interest to researchers. The changes brought about by a move to an information-based society will allow homes to integrate more fully into local, national and international groupings. This will, however, also have the opposite effect in some areas with the information society outsiders - the "un-informationed" being at a disadvantage should the information society become the main societal model in use. There are a number of areas where the information society is being developed on this interface. Three of these areas are outlined here.

eShopping is a common activity in households where the use of the Internet has become more than a novelty. There are now many companies who specifically design eShopping web sites so that home users can order goods and services online and reduce the necessity for travel and searching through shops. There is much said about the benefits of eShopping and its usefulness but less said about the opposite problems. Positive aspects are the reduction in time spent in stores, travel to and from shops, etc the negative aspects are the increase in isolation, the necessity to pay extra for the service which can deter those that may really need it and often the lack of choice in goods offered for purchase. Research on the comparative shopping experience needs to be done to focus on the future needs of the home users in this important information society activity.

eGovernment is now a common topic of discussions, conferences and projects. The move to more open forms of government is often given as a major factor in the development of more online forms of government. 
Whilst it may be true that the use of ICT may lead to more direct involvement by people in their government, it is also prone to the same problems of unrepresented minorities as the more traditional system. Solving the lack of participation will require more than a move to eGovernment and is not adequately addressed. Taking part in the eSociety will be a major area where the home and its ICT can play a part in the future.

eHealth is also an area that has received much attention. Many of the educational messages on health have been difficult to implement because of the lack of an adequate channel for them to reach the required audience. With the home embedded in the information society, the health concerns of individuals can be addressed by direct use of ICT in order to access health information and use it to interact with daily life. For example, health requirements can be programmed into home systems, which could then monitor food ordering information, so that suggested menus could take account of dietary requirements. Many of the systems in use today could do these simple tasks. With ubiquitous computing within the home, they will form a more reliable interface with the information coming from outside the home.

There are many other areas where society and the home meet and this is one of the main arenas of the information society that will shape its final form. The home is a central pivot of society and the way in which it is embedded in society is crucial to the shape that society will take in any future model; be it an information society or some other model not yet envisaged.

\section{Interpersonal communication}

A fundamental activity of human society is communication between people. Current levels of civilisation have been built on communication, since without effective means of exchanging ideas, human thoughts and concepts would remain individual. This is true in a home setting also. The structure and organisation of the home relies on communication between the individuals who live in the home space. This interaction is also critical to the everyday function of the home entity. The occupants need to communicate to keep the home environment running smoothly and to coordinate their individual activities.

Inter-personal communication can take many forms and many of these are used in the home at present. Voice, text and non-verbal communication are common and typical situations are easy to find. In an information society with the shape of the home changing the use of ICT to mediate this communication is seen as being an adjunct to the more familiar forms of 
everyday transmissions. A number of research projects are investigating these aspects of home life. Some of these are concentrating on a direct analogy to current forms of communication whilst others are looking at the use of technology to provide new avenues of contact between people in the home. Examples of the former are the work of Harris, Huang and Sloane [6] who are using the concept of the home information system to validate the use of web-mediated communication in a virtual, distributed home setting. Of the latter, there are a number of projects that are using technology to support communication in new ways. Communicating photo-frames[12], where images are enclosed by a frame that can use emotional parameters to exchange low-level information between users; and family-ware[4] where devices are used to link related individuals, thus giving them a sense of contact without direct voice or text exchange. More research in these areas is being conducted showing how technology can assume a role that serves the needs of people in the home environment. What is now clear from other projects is that the use of technology will find a way into everyday life if it is useful to people. Examples of this are the increasing use of email and mobile text messaging to keep in contact.

\section{People-technology}

The final interaction of interest is that between people and technology. This has been an area of study for a long time with many different perspectives being found to analyse the interface and the interaction between the objects of interest. There are a number of perspectives that have been developed to study the use of computers, most of which are used in the work environment. However, the home presents a different problem, as discussed earlier.

The social setting of the home requires a different rule base for the design of equipment. The assumptions that are relevant in the workplace no longer hold true. It is unlikely that the home's occupants will have access to extensive training, will want to invest time in learning difficult operating procedures, will use specifically designed ancillary equipment, such as workstations or have room to devote to equipment outside of multi-purpose living areas (or even want to do so). All these factors tend to create a situation that renders traditional analysis redundant and creates a situation that requires specific attention. 


\section{THE INFORMATION SOCIETY}

The move to an information-based model of society will, therefore, present problems for home dwellers and the designers of homes and the technology that is associated with them. With this in mind it is useful to broaden the discussion to cover those aspects of the information society that are relevant to homes and to see what are the factors that are particularly important to the study of the home in this new model of society. This section will look at the general effect on homes and people, the telematic systems that will be available and discuss some of the issues that arise from their use and the models of organisation that are envisaged.

\section{The effect on homes}

The move from a mainly industrial society to one where the majority of individuals process information allows, but does not ensure or enforce, a move away from the centralised workplace to a distributed model that can be based on the home. The home can then be seen as the main unit of organisation in the information society. This leads to the home needing to employ an infrastructure that will allow it to function effectively in this setting, not only as a place of leisure and entertainment as at present, but also as a place of work and production. The infrastructure requirements of homes have also been the subject of some study with the ideas of residential gateways [13] and home network architectures [3] being common topics. What is also required is an integration of the technical and social aspects of the study of these systems, so that the user's requirements can feed into the technical specification and thereby produce systems that are flexible, adaptable and useable in the home environment. The split between the technical and social has not been of benefit to users in the workplace setting and is even less likely to benefit home-based users. The effect on people being more dramatic when their home is the scene of the interaction.

\section{The effect on people}

The move from an industrial society to an information society and its attendant re-organisation will create greater focus on the home as it becomes more of a work environment than it is at present. This will have a number of effects on the people who inhabit the home, some of which are evident in current society where home dwellers attempt to mix the functions of home.

Disparity of function. There is a difficulty when a structure has a dual purpose of not having clear delineation between the various functions it is designed to accommodate. In the case of a home it is even more problematic 
since most homes, at present, are not designed for work in addition to normal living. This creates a disparity between the home and the function that is trying to co-exist with it. This is likely to be less of a problem when homes are designed with the information society in mind but there is a large legacy of current building stock that is unsuitable for the move to the information society.

Peer/Family group expectations. Another area of disparity is between the requirements of work and home life. This is currently a problem in many areas but the stricter delineation between the place of work and home allows for easier management of the problem. For example, when at the workplace people can concentrate on the work task without reference to the home, and the same can be done in the home with the different locations being a useful dividing line. When the home is also the workplace, the worker/home dweller needs to have a better sense of the balance between the tasks of each and be able to function in both environments concurrently, as well as being able to switch modes between home and work.

Work place pressures/politics. The other problem of a move to using the home as a workplace is the divide between those that work at home and those that use a traditional workplace. There are problems of contact with colleagues and not being seen to be part of workplace groupings. This can affect the individual in a number of ways that can be detrimental to career development. This may be a transitional problem, a complete move to a fuller implementation of an information society renders it probable that less workers will be centrally located and the business will be more virtual. The problems will not then be those of the individual, but those of the whole group and their communication between each other. This is likely to be much fairer for individuals than the current transitional problems of those few workers using the home as a workplace. However, the move will need to be well-managed to make it as effective and fair as possible.

\section{Security/Sharing of information}

One of the aspects of the information society is the possibility of new modes of living in the home. A move to more virtual presence and contact with the home is already taking place with some virtual parts being added on to existing home modes of life. For example the use of the Internet to form alliances and exchange information between people who are widely separated is a common phenomenon of the late $20^{\text {th }}$ and early $21^{\text {st }}$ centuries. The models of home organisation in an information society may include more virtual presence still with people sharing their information between trusted individuals such as family members who are dispersed and living in other places. 
This then leads to the concept of the distributed home where a number of physical spaces are connected together via their information resources and share their data and systems to the extent of forming a single entity of a distributed home. There are obvious limitations of systems such as these but the advantage of using information in this way is to remove the barriers that the distance between people has created

However, when models such as these are used, there is more necessity to ensure that the information being exchanged is secure and confidential as it is likely to be personal. Current systems designed for secure transmission of information in a commercial environment are adequate but often unwieldy in a domestic situation. Secure systems need to be used automatically to ensure that such a scenario is feasible.

\section{Home information systems}

To facilitate the scenarios envisaged in the previous section, the home computer needs to evolve towards a more comprehensive system that can be used to host the many functions of the home that can be performed electronically. There are many functions that can be automated and connected in the home and these have seen many different applications over the years and a number of systems are available to perform these automated functions. However, the home is a considerable user of information in its many forms and this is an area where more automated responses and storage are needed.

Some devices are now being marketed with limited functionality in this area but they are directed at single functions rather than being a comprehensive solution to the problem of organising information in the home. The systems are, however, being studied in research labs and projects around the world and a number of systems are likely to be available in the near future. How they will be used, and how people interact with them will be another area of study that will be of interest once they are more widely available.

\section{Mobility}

One final aspect of the home in the information society that will become more relevant as people learn to live with the new paradigm, is the increase in mobility that is afforded by the move. Already, people embrace mobile technology even though it is still fairly limited compared with the promise of third generation systems. The type of systems available at present will seem very under-powered and limited when the new networks finally appear and the devices that are promised actually materialise. 
The move to the next generation will allow more computing power to be used along with higher speed connections and consequently there will be fewer differences between mobile and stationary systems in terms of functionality and connectivity.

The effect of this on people in an information society is likely to be the removal of barriers to mobility. The requirement to be situated in one place is often forced on the individual by the necessity to perform the work function at a specific location. With this need diminished or removed the possibility of a mobile lifestyle is more practical. It is likely to be a number of years from the introduction of the necessary systems before the effects are widely noticeable. In the meantime, the link between function and location is increasingly becoming redundant as more virtual means of communication are used between people, with telephones and email increasingly replacing face-to-face and paper communications.

\section{SOCIAL EFFECTS OF THE INFORMATION SOCIETY}

There a number of effects that the information model will have on society itself. Most of these have been documented widely in the literature and are worth considering although there is often little evidence of them being widely applicable as yet. The effects on groups and individuals in society is often stated and the opposite sides of the various arguments are worth considering. For example, the relative move towards inclusion or exclusion, wider integration or isolation, more or less mobility and wider or restricted choice.

Exclusion - Inclusion. The debate over the inclusive or exclusive nature of the information society is sure to be held widely for many years with examples of both effects being evident. The argument for exclusion usually centres around the cost of the technology to access the features that determine the information society with computers and telephone charges being the main determinants of the cost involved. On the other hand the cost has been steadily falling over the 20 years since the introduction of the personal computer, both in the actual cost and, consequently, in terms of the inflation-adjusted figures. However, the cost of access is still above the threshold of acceptability for many homes, especially when compared to more traditional forms of access to information such as television and radio. The inclusive nature of the technology is often stated as being related to its ability to level out the differences of access to information with different types of equipment being able to access the same information. Access to information and inclusion in the online world is also less determined by the 
need for monetary resources as it is by the requirement to have the time available to contribute or browse.

These opposite effects of exclusion and inclusion are more symptomatic of a transition in society than a finalised change. There have always been disadvantaged groups in society and the information society is not likely to be different, but the question of whether it is the technology or society itself that is the cause of the disadvantages cannot yet be determined.

Integration - Isolation. Similar to the previous argument there are two opposing views on the nature of the integrative function of the information society. The effect that the technology has in the direction of integration is that the differences between people are not apparent in the anonymous world of cyberspace, where race, gender, age and other personal characteristics can be forgotten, removed or replaced. This can lead to a more integrative experience but tends to apply only for those that are taking part in the particular area of interest. It also tends to isolate the individual with differing views or characteristics. Some interesting studies have been published with this embryonic virtual space and they show the different attitudes that are prevalent in society being translated into cyberspace [2], [14].

Mobility. The actions that militate for increased mobility are typified by the move to third generation systems with higher bandwidth, the increasing take-up of mobile services and devices and the general move by society to be available online at anytime. The opposite of this is the need to remain private and to be able to be detached from the everyday world when necessary. Increasingly, the use of mobile devices removes personal choice by requiring full availability, yet there are many times when it is necessary to be apart from the workplace or the home without interruption. This is increasingly important when it is becoming more necessary to manage the use of personal time in a coherent manner. For example, a person may be employed by two or more different employers, be learning from home and have family commitments to manage - it makes it much more difficult to do this effectively if demands from one of the employers exceed the time available, remunerated or allotted by the worker.

Choice. Finally the move to more or less choice is an area of interest to those that study the information society. The indicator for greater choice is that the wider spread of the Internet has given individuals access to more sources of information, services and goods than was possible before it became as widespread as it has. The opposite factor of less choice is evident in some systems where standards for software and hardware do not provide the user with a viable choice of alternative system.

There are many factors that could be used in this discussion and the theme is along similar lines to the above discussions. There are often 
positive and negative effects from the information society that are not yet fully developed and may change with time so that they are, as yet, unclear.

\section{DISCUSSION AND CONCLUSION}

This chapter has outlined the place that is envisaged for the home in the information society and the various effects that will be in evidence when the move to an information-based model is more complete. However, this analysis has also highlighted the need for restraint in reading too much into the current outlines that have been put forward as there are still many different paths that could result in many different styles of society. The central area that is occupied by the home in society is seen as being a continuing part of any model of society, even where the definition of the home is subject to change, as is possible with the technological changes that can affect it.

Therefore, answering the question of what will determine the path of the information society is difficult, since there are so many factors, influences and possible options that all play a part in the movement from the current model to a new one. What has happened in the past may determine the way this change occurs, but it may be that a new consensus emerges that does not depend on previous changes and transitions. However, the people and homes that make up society will all play a part in its structure and development and the central role that the home now plays in society is likely to be increasingly important with the move towards a more home-based model of work. As was indicated at the beginning it is also clear that the home itself should not be the prime area of concern for designers, but rather the interactions of its occupants with the various other objects and actors that influence their daily lives.

What has also become clear from this and other chapters in this book is that the information society has led to a blurring of boundaries. In the case of the home, this is seen as the extension of the definition of home to incorporate the virtual and distributed nature of cyberspace, with home being the area where the real and virtual can co-exist. The boundaries between real-life home and cyber home are becoming less important, with people happily co-existing between of the two. This incorporation of "virtual life" into the real home is likely to be one of the defining aspects of the information society. 


\section{REFERENCES}

1. Benjamin (1995) (Ed.), The Home: Words, interpretation, meanings and environments, Ashgate, Aldershot, UK.

2. Dibbell J. (1999), My tiny life, $4^{\text {th }}$ Estate, London, ISBN 1-84115-058-4

3. Edens G. T. (2001), Home networking and the CableHome project at Cablelabs, IEEE Communications magazine, June 2001, 112-121

4. Go K., Carroll J. and Imamiya A. (2000), Familyware, in Sloane A. and van Rijn F. (Eds.), Home Informatics and Telematics: Information, Technology and Society, Kluwer Academic publishers, Boston MA., ISBN 0-7923-7867-9

5. Haddon L. and Silverstone R. (2000). Information and communication technologies and everyday life: Individual and social dimensions, in Ducatel K., Webster J. and Hermann W., (2000) The Information Society in Europe: Work and life in an Age of Globalisation, Rowman and Littlefield, Lanham MA ISBN 0-8476-9590-5

6. Harris A., Huang W. and Sloane A. (2000), Web-based family noticeboard in: Sloane A. and van Rijn F. (Eds.), Home Informatics and Telematics: Information, Technology and Society, op. cit. [4].

7. Junestrand S. and Keijer U. (2000), Measuring and evaluation of ICTsupported services in the domestic environment, in: Sloane A. and van Rijn F. (Eds.), Home Informatics and Telematics: Information, Technology and Society, Volume 2, IFIP, ISBN 3-901882-12-X

8. Junestrand S., Keijer U. and Tollmar K. (2001), Private and public digital domestic spaces, Int. J. Human-Computer Studies, 54, 753-778

9. Kjaer A., Madsen K. H., and Petersen M. G., (2000), Methodological Challenges in the study of technology use at home, in Sloane A. and van Rijn F. (Eds.) Home Informatics and Telematics: Information, Technology and Society, op. cit. [4].

10. Lawrence R. J. (1995), Deciphering home: An integrative historical perspective, in Benjamin (ed.), op. cit. [1].

11. Monk A. (2000) User-centred design: The home use challenge, in: Sloane A. and van Rijn F. (Eds.) Home Informatics and Telematics: Information, Technology and Society, op. cit. [4].

12. Mynatt E. and Rowan J. (2000) Cross-generation communication via digital picture frames, in: Sloane A. and van Rijn F. (Eds.), Home Informatics and Telematics: Information, Technology and Society, op. cit. [7].

13. Nguyen T.-A. and Bouwen J. (2001), The next-generation residential gateway, J. Inst Brit. Telecom Eng, 2, 3, 134-138.

14. Rheingold H. (1994), The virtual community, Secker and Warburg, London ISBN 0-436-20208-5 
15. Silverstone R. (1993), Domesticating the revolution: Information and communication technologies and everyday life, ASLIB Proceedings, 45(9), 227-233.

16. Sloane A. (1994), Homelink: An international collaboration for HOIT, in: IFIP Transactions A, Volume 53, North Holland, 142-147, ISSN 0926-5473.

17. Sloane A. (1995), The distributed home environment and the new OIKOS, in: A. Dix \& R. Beale (Eds), Remote Co-operation: CSCW issues for mobile and teleworkers, Springer, London. ISBN 3-540-76035-0.

18. van Rijn F., Bjerg K. and Frerk G. (1992), Perspectives on Home-oriented Informatics and telematics, in: Aiken R. M. (Ed.), Information processing ' 92 , IFIP Transactions A-13, Education and Society, North Holland, ISBN 0-44489748-8, 494-507.

19. Wise J. M. (2000), Home: Territory and identity, Cultural studies, 14(2), 295310. 